\title{
Effect of aminophylline on respiratory muscle strength after upper abdominal surgery: a double blind study
}

\author{
N M Siafakas, A Stoubou, M Stathopoulou, V Haviaras, N Tzanakis, D Bouros
}

\begin{abstract}
Background-The effect of aminophylline on maximum respiratory muscle strength in patients undergoing upper abdominal surgery was investigated.

Methods-An open pilot study was performed in which aminophylline was administered continuously for 48 hours after surgery (protocol I). In a second group of subjects aminophylline was given for 24 hours after cholecystectomy in a double blind placebo controlled trial (protocol II). Twelve patients participated in the pilot study (group A) and 25 in protocol II of which 14 received aminophylline (group B) and 11 placebo (control, group C). Respiratory muscle strength was assessed by measuring mouth pressures during maximum static inspiratory and expiratory efforts. Forced expiratory volume in one second $\left(F E V_{1}\right)$, forced vital capacity (FVC), vital capacity (VC), inspiratory maximum pressures (PImax), expiratory maximum pressures (PEmax) were measured 24 hours preoperatively, Pimax and serum theophylline 24 hours postoperatively, and FEV 1 , FVC, VC, Pimax, PEmax, and serum theophylline 48 hours after surgery.
\end{abstract}

Results-FEV, FVC, and VC decreased in all groups of patients at +48 hours. Pimax fell at +24 hours and +48 hours but this decrease was significantly smaller in the two groups who received aminophylline than in the control group. Pemax showed a decrease at +48 hours but this reduction was similar in all three groups studied, independent of the treatment given. These data suggest that either aminophylline had a protective effect only on the inspiratory muscles or, most probably, that the effect of aminophylline was central, reducing the phrenic nerve inhibition induced by cholecystectomy and thus improving diaphragmatic function.

Conclusions-Upper abdominal surgery decreases inspiratory and expiratory muscle strength and aminophylline has a protective effect only on inspiratory muscle function. This may have important clinical applications in minimising pulmonary complications after cholecystectomy.

(Thorax 1993;48:693-697)
A number of pulmonary complications have been recognised in patients after upper abdominal surgery. ${ }^{1-4} \mathrm{~A}$ restrictive ventilatory defect is the usual change in lung function and is characterised by a significant reduction in vital capacity (VC) and in functional residual capacity (FRC). ${ }^{5-7}$ Diaphragmatic dysfunction has been suggested to be an important factor in this postoperative pattern of lung function. ${ }^{8-10}$ The mechanisms of altered diaphragmatic function, however, are not yet clearly understood. The effects of anaesthesia and pain on the diaphragm, phrenic nerve inhibition, diaphragmatic fatigue, and changes in the regulation of breathing may all be implicated. ${ }^{7-12}$

The aim of this study was to investigate respiratory muscle strength after upper abdominal surgery to assess the response of neuromuscular respiratory function to a maximum respiratory effort. This was of particular interest because, when severe pulmonary complications occur, the respiratory system may be working at maximum capacity.

Aminophylline has been shown to reverse the reduction of diaphragmatic activity during quiet breathing after cholecystectomy. ${ }^{13} \mathrm{We}$ therefore wished to assess the effect of aminophylline on respiratory muscle strength after upper abdominal surgery. Aminophylline was administered for $\mathbf{4 8}$ hours after surgery in an open trial (pilot study) and was found to have a protective effect only on the inspiratory and not on the expiratory muscle strength. This was followed by a double blind placebo controlled trial in which the drug was given for 24 hours after cholecystectomy.

\section{Methods}

SUBJECTS AND ANAESTHESIA

Thirty seven patients $(10$ men and 27 women) who underwent cholecystectomy were studied. All patients were non-smokers and none was found by routine preoperative evaluation (chest radiography, ECG, physical examination, and lung function tests) to suffer from any cardiopulmonary or neuromuscular disease.

All patients were informed of the nature of the investigation, which was approved by the Ethics Committee of our hospital, and gave their consent. An elective cholecystectomy was performed in all patients by the same surgical incision (right paramedian) and under similar anaesthetic and analgesic control, with $5 \mathrm{mg}$ diazepam and $0.1 \mathrm{mg}$ fentanyl as pre- 
medication. Anaesthesia was induced with thiopentone $(5 \mathrm{mg} / \mathrm{kg})$ and fentanyl $(0.005-0.01 \mathrm{mg} / \mathrm{kg})$ and maintained by a gas mixture of $\mathrm{N}_{2} \mathrm{O} / \mathrm{O}_{2}$ (4/2) under controlled ventilation. Additional fentanyl and pancuronium were given to achieve the required muscle relaxation. Atropine $0.015 \mathrm{mg} / \mathrm{kg}$ and neostigmine $0.03 \mathrm{mg} / \mathrm{kg}$ were given at the end of surgery. Pain control was the same in the three groups of patients during the postoperative period. Specifically, pethidine $1 \mathrm{mg} / \mathrm{kg}$ was given intramuscularly every six hours for 48 hours. Only two patients required an additional injection of pethidine during the first 24 hours after operation.

Figure 1 summarises the study design, the administration of aminophylline, and the measurements made during the two studies.

PROTOCOL I: OPEN TRIAL (PILOT STUDY)

In 12 consecutive patients (group A) aminophylline was administered immediately after the end of the operation and for 48 hours thereafter. Immediately after extubation aminophylline was given as a bolus, $6 \mathrm{mg} / \mathrm{kg}$ intravenously, and thereafter as an infusion at a rate of $0.9 \mathrm{mg} / \mathrm{kg} /$ hour in $5 \%$ dextrose solution for 48 hours. Aminophylline serum concentrations was measured by an enzyme multiplied immunoassay technique with an automatic counter (Gilford 203S). FEV FVC, and VC were measured 24 hours before surgery ( -24 hours) by a dry spirometer (Vitalograph, Buckingham, UK) and corrected to BTPS. Maximum static inspiratory (PImax) and expiratory (PEmax) pressures were measured according to the method of Black and Hyatt in the sitting position. ${ }^{14}$ PImax was measured near residual volume and Pemax near total lung capacity. Minimum duration for an accepted effort was one second. At least three efforts were recorded and the maximum value taken when the variability was less than 5\%. Both manometers (Moxam, Paris) used to measure positive and negative pressures had two needles, one of which stopped at the level of the maximum pressure for accurate pressure measurement. The examiner ensured that the duration of maximum effort was greater than one second by observing both needles during the procedure. Details of the method have been described previously. ${ }^{15}$ PImax was measured at the patient's bed in a semirecumbent

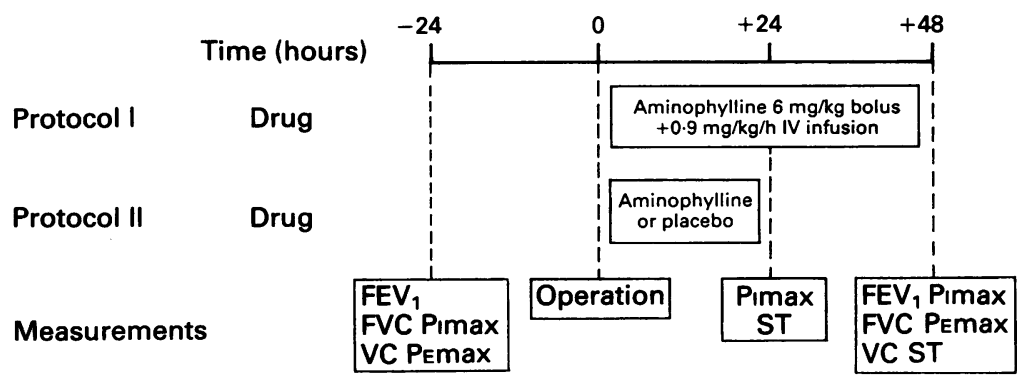

Figure 1 Experimental protocols. Protocol I (pilot study): open administration of aminophylline (48 hours); protocol II: double blind placebo controlled trial (24 hours). $S T$-serum theophylline. position 24 hours postoperatively ( +24 hours) and blood was taken for the determination of theophylline levels. $\mathrm{FEV}_{1}, \mathrm{FVC}$, VC, PImax, and PEmax were measured 48 hours postoperatively ( +48 hours) in the sitting position and blood taken for a further measurement of the level of theophylline.

PROTOCOL II: DOUBLE BLIND TRIAL

In 25 patients aminophylline or placebo was administered immediately after the operation for 24 hours in a double blind fashion in random order. Aminophylline or placebo (normal saline solution) was given as a bolus, $6 \mathrm{mg} / \mathrm{kg}$ intravenously, and then as an infusion at a rate of $0.9 \mathrm{mg} / \mathrm{kg} / \mathrm{hour}$ in $5 \%$ dextrose solution for 24 hours. $\mathrm{FEV}_{1}$, FVC, VC, PImax, and PEmax were measured 24 hours before surgery ( -24 hours) in a sitting position. Pimax was measured at the patient's bed in semirecumbent position 24 hours postoperatively (+24 hours). Serum theophylline was also determined but not revealed to the investigators. The biochemistry department was instructed to break the code only when theophylline measurement was greater than $20 \mu \mathrm{g} / \mathrm{dl}$ to avoid potential toxic effects. However, no such event occurred during the study. FEV 1 , FVC, VC, PImax, PEmax, and serum theophylline were measured 48 hours postoperatively in the sitting position.

Upon completion of the study patients who received the placebo served as the control group (group $\mathrm{C}$ ) and those who received aminophylline as group B.

\section{STATISTICAL ANALYSIS}

The Microstat (ECOSOFT, Indianapolis, USA) computer program was used for statistical analysis of the data. The results are shown as mean (SE). All variables showed a normal distribution and the significance of the difference in the mean values was calculated by the Student's $t$ test. In addition the differences in the mean values were estimated by the ANOVA two way test and the Bonferroni modified $t$ test. $\mathrm{p}<0.05$ was considered significant with the Student's $t$ test and $\mathrm{p}<0.016$ for the Bonferroni test.

\section{Results}

Anthropometric data, mean duration of $\underset{<}{0}$ anaesthesia, and preoperative values of the $Q$ parameters measured in the three groups of $\bar{D}$ patients are shown in table 1. All groups had ? similar anthropometric data and their mean values of $\%$ predicted $\mathrm{FEV}_{1}, \mathrm{FVC}, \mathrm{VC}^{16}$ and $\frac{\mathrm{D}}{\mathbb{D}}$ maximum pressures did not differ significantly 24 hours before surgery. In addition, the mean duration of the operation was similar for the three groups.

The mean values of the variables measured 24 hours and 48 hours after surgery are summarised in table 2 . The mean value of serum theophylline was within the therapeutic range $(10-20 \mu \mathrm{g} / \mathrm{dl})$ in groups $\mathrm{A}$ and $\mathrm{B}$ at +24 hours and in group $A$ at +48 hours. No individual had levels outside the therapeutic range during the study. 
Table 1 Mean (SE) anthropometric data, duration of anaesthesia and preoperative measurements in the three groups of patients

\begin{tabular}{|c|c|c|c|}
\hline Variable & $\begin{array}{l}\text { Group } A \\
\text { (aminophylline } 48 \text { hours) }\end{array}$ & $\begin{array}{l}\text { Group B } \\
\text { (aminophylline } 24 \text { hours) }\end{array}$ & $\begin{array}{l}\text { Group C } \\
\text { (placebo) }\end{array}$ \\
\hline $\mathbf{n}$ & 12 & 14 & 11 \\
\hline Men & 3 & 4 & 3 \\
\hline Women & 9 & 10 & 8 \\
\hline Age (years) & $49.8(3.56)$ & $55 \cdot 6(2 \cdot 75)$ & $50(3.4)$ \\
\hline Weight (kg) & $66 \cdot 4(2 \cdot 25)$ & $70 \cdot 2(3 \cdot 2)$ & $74(3 \cdot 2)$ \\
\hline Height (cm) & $159(2 \cdot 6)$ & $159(2 \cdot 7)$ & $161(3 \cdot 3)$ \\
\hline Anaesthesia (min) & $59(4 \cdot 9)$ & $63(3.74)$ & $61(3.9)$ \\
\hline PImax (kPa) & $6.96(1 \cdot 14)$ & $8.53(0.76)$ & $8.83(1.3)$ \\
\hline PEmax (kPa) & $9 \cdot 12(1 \cdot 16)$ & $10 \cdot 2(1 \cdot 36)$ & $10(1 \cdot 36)$ \\
\hline $\mathrm{FEV}_{1}$ (\% pred) & $119(6 \cdot 1)$ & $113(6 \cdot 4)$ & $111(3 \cdot 8)$ \\
\hline FVC (\% pred) & $107(3 \cdot 5)$ & $118(4 \cdot 5)$ & $109(4 \cdot 6)$ \\
\hline $\mathrm{FEV}_{1} / \mathrm{FVC}(\%)$ & $82(1 \cdot 7)$ & $80(1.4)$ & $79.5(2.9)$ \\
\hline VC (\% pred) & $115(7 \cdot 2)$ & $119(4 \cdot 3)$ & $110(4 \cdot 7)$ \\
\hline
\end{tabular}

Mean values A $v \mathrm{~B}, \mathrm{~A} v \mathrm{C}, \mathrm{B} v \mathrm{C}$ not significantly different $(\mathrm{p}>0.5$, Student's $t$ test; $F<0.937$, ANOVA).

Figure 2 shows the mean (SE) value of Pimax before $(-24$ hours) and after $(+24$ hours and +48 hours) surgery. Pressures are expressed as a percentage of their preoperative values. It can be seen that PImax decreased significantly from its preoperative value 24 hours after surgery in all three groups (group A: $p<0.05$, group $\mathrm{B}: \mathrm{p}<$ 0.001 , group C: $p<0.001$ ). This decrease in PImax was less in the patients receiving aminophylline (groups A and B) than in the control group (group $\mathrm{C}$ ), and the differences in the mean values of PImax at +24 hours between the aminophylline group and controls were statistically significant (A $v$ C, B $v$ C, $p<0.05$ ) (table 2). The mean value of PImax in the two groups that received aminophylline was almost double that of the control group at +24 hours (fig 2 , table 2 ).

The mean value of PImax increased by 48 hours after surgery in all three groups of patients (fig 2), but the significant difference in the mean values of Pimax of groups $A$ and $B$ against $C$ persisted (table 2). The mean value of PImax for group A at +48 hours was similar to the preoperative value, but for groups $B$ and $C$ it remained below the preoperative values $(p<0.005$ and $p<0.001$ respectively).

The mean (SE) values of PEmax before and 48 hours after surgery are summarised in fig 3. At +48 hours the mean value of PEmax was significantly reduced from its preoperative value in all groups of patients (group A: p < 0.05, group B: p $<0.05$, group C: $p<0.001)$. The mean values of PEmax for

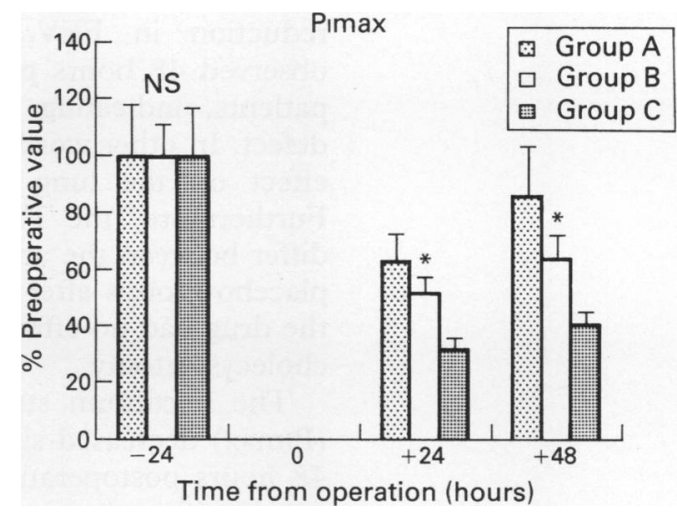

Figure 2 Mean (SE) maximum inspiratory pressure (PImax) shown as a percentage of preoperative value. Group $A$-aminophylline for 48 hours, group $B$-aminophylline for 24 hours, group $C$-control group. Measurements made 24 hours before surgery

( -24 hours), 24 hours and 48 hours after surgery (+24 hours, +48 hours). NS-no statistical significance; *statistically significant difference between the mean values at -24 hours, +24 hours, +48 hours.

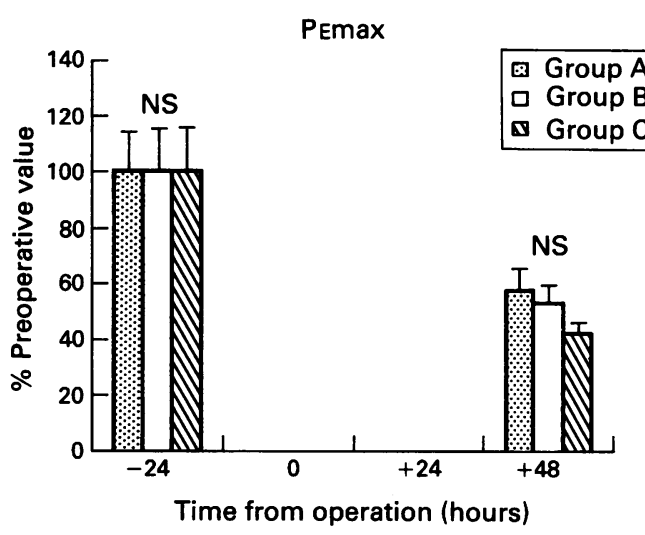

Figure 3 Mean (SE) maximum expiratory pressure (PEmax) as a percentage of preoperative value in the three groups of patients at -24 hours and +48 hours.

(For definitions see fig 2.)

the three groups were, however, similar.

The mean values of $\mathrm{FEV}_{1}, \mathrm{FVC}$, and VC decreased significantly from their preoperative values 48 hours after surgery in all three groups of patients $(p<0.05)$. This decrease was similar in each group (table 2 ).

\section{Discussion}

Our results have confirmed previously reported changes in the respiratory system after upper abdominal surgery. ${ }^{1-6} \mathrm{~A}$ significant

Table 2 Mean (SE) measurements 24 and 48 hours after surgery

\begin{tabular}{|c|c|c|c|c|c|c|c|}
\hline \multirow[b]{2}{*}{ Time } & \multirow[b]{2}{*}{ Variable } & \multirow{2}{*}{$\begin{array}{l}\text { Group A } \\
\text { (aminophylline } 48 \text { hours) }\end{array}$} & \multirow{2}{*}{$\begin{array}{l}\text { Group B } \\
\text { (aminophylline } 24 \text { hours) }\end{array}$} & \multirow{2}{*}{$\begin{array}{l}\text { Group C } \\
\text { (placebo) }\end{array}$} & \multicolumn{3}{|l|}{$p$ value ${ }^{*}$} \\
\hline & & & & & $A \mathrm{v} B$ & $A$ v $C$ & $B \vee C$ \\
\hline+24 hours & $\begin{array}{l}\text { Pimax }(\mathbf{k P a}) \\
\text { Serum theophylline }(\mu \mathrm{g} / \mathrm{dl})\end{array}$ & $\begin{array}{l}4 \cdot 32(0 \cdot 54) \\
14 \cdot 3(0 \cdot 29)\end{array}$ & $\begin{array}{l}4.32(0.45) \\
15 \cdot 6(0.13)\end{array}$ & $\begin{array}{l}2 \cdot 8(0 \cdot 24) \\
-\end{array}$ & $<0.001$ & $<0.05$ & $<0.05$ \\
\hline+48 hours & 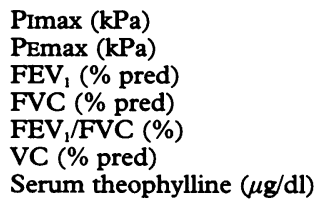 & $\begin{array}{l}5 \cdot 9(0 \cdot 85) \\
5 \cdot 3(0 \cdot 9) \\
77 \cdot 4(5 \cdot 2) \\
79(4 \cdot 8) \\
76(1 \cdot 7) \\
78(5 \cdot 8) \\
16 \cdot 6(0 \cdot 38)\end{array}$ & $\begin{array}{l}5 \cdot 5(0 \cdot 7) \\
5 \cdot 4(0 \cdot 86) \\
82(4 \cdot 5) \\
88(4 \cdot 5) \\
75(2 \cdot 2) \\
89(3 \cdot 5) \\
2 \cdot 6(0 \cdot 13)\end{array}$ & $\begin{array}{l}3 \cdot 5(0 \cdot 32) \\
4 \cdot 2(0 \cdot 5) \\
70(3 \cdot 6) \\
81(3 \cdot 6) \\
69(3 \cdot 0) \\
84(3 \cdot 3) \\
\end{array}$ & $<0.001$ & $<0.05$ & $<0.05$ \\
\hline
\end{tabular}

^Only significant differences shown. 
reduction in $\mathrm{FEV}_{1}, \mathrm{FVC}$, and VC was observed 48 hours postoperatively in all our patients, indicating a restrictive ventilatory defect. In other words, aminophylline had no effect on the lung volume measurements. Furthermore, the $\mathrm{FEV}_{1} / \mathrm{FVC}$ ratio did not differ between the aminophylline treated and placebo groups after surgery, suggesting that the drug had no effect on airway calibre after cholecystectomy.

The maximum static inspiratory pressure (PImax) decreased significantly 24 hours and 48 hours postoperatively, and this reduction was significantly greater in the control group than in the two aminophylline groups. These results clearly show a protective effect of aminophylline on inspiratory muscle function and agree with the results of Dureuil et al who investigated the diaphragmatic contribution to quiet breathing and showed an early reduction of diaphragmatic activity after upper abdominal surgery. ${ }^{13}$ They also showed that this reduction was partially reversed by aminophylline during quiet breathing. Although the mechanics of the maximum static inspiratory effort and those of quiet tidal breathing are different, our results suggest that the effect of aminophylline after surgery was similarly protective. Furthermore, our studies were conducted in both open and double blind protocols while Dureuil et al administered aminophylline only in an open trial. ${ }^{13}$

Ford et al measured transdiaphragmatic pressure and showed a significant reduction in diaphragmatic activity after upper abdominal surgery. ${ }^{8}$ This reduction returned towards normal at 24 hours after surgery and had reached normal levels at 48 hours. Our results showed that PImax in the control groups was still reduced from its preoperative value at +48 hours suggesting that the maximal strength of the diaphragm had not been fully restored.

Our results are also in agreement with those of Simonneau et al who found diaphragmatic dysfunction during quiet inspiration and maximum inspiratory effort after upper abdominal surgery ${ }^{9}$ which lasted for about one week. In accordance with those observations our control group showed a significant decrease in PImax at 24 hours and 48 hours after surgery, and PImax was $31 \%$ and $40 \%$ of its preoperative value at +24 hours and +48 hours in the control group.

Although a trend was apparent (fig 3), we did not find a significant effect of aminophylline on the strength of expiratory muscles as assessed by the PEmax. We were unwilling to measure PEmax at 24 hours after surgery in case we damaged the healing of the incision.

It is well known that posture affects the maximal respiratory pressures. A criticism of our results could therefore be that we made the measurements of Pimax at +24 hours in a different position (semirecumbent) from those made at -24 hours and +48 hours (sitting). This posture effect was similar for all groups of patients, however, whether receiv- ing aminophylline or not. Another limitation of our design was that we did not estimate postoperative pain, or the stage of consciousness, or both, by a visual analogue scale. All necessary precautions were taken, however, to use similar anaesthetic and analgesic agents in the same doses for all patients. The double blind placebo controlled design of the second part of this study makes it unlikely that these factors could have affected the results. Although maximum pressures are dependent on effort, ${ }^{17}$ the randomisation of the patients in the second study made it unlikely that there were significant differences in personality or motivation between the control and aminophylline groups.

PImax is an estimate of global inspiratory muscle strength, and we can only postulate that the results reported in this study were due to the effect of aminophylline on diaphragmatic function alone. Diaphragmatic strength is dependent on the action of other muscles, particularly those stabilising the ribcage. There are reasons to suggest, however, that the effect of aminophylline we observed could be a specific one, exerted mainly on the diaphragm. The magnitude of the effect of aminophylline was significantly greater than that reported by others. ${ }^{18-20}$ The effect was not therefore specifically on diaphragmatic contractility but on the phrenic nerve inhibition reflex. Dureuil et al ${ }^{10}$ showed that diaphragmatic contractility was not altered after upper abdominal surgery and postulated that the observed diaphragmatic dysfunction was secondary to reflex inhibition of the phrenic nerve output. The action of aminophylline seen in our study could therefore be due to an effect on the central nervous system that might reverse postoperative reflex phrenic inhibition. Additional studies are needed to compare aminophylline with drugs having only an inotropic effect (for example, digoxin) or a central stimulant effect (for example, doxapram) to clarify such mechanisms of diaphragmatic impairment and the mode of action of aminophylline.

The positive effect of aminophylline on inspiratory, but not on expiratory, muscle strength makes it more probable that the explanation of the mode of action of aminophylline is a specific one and not just an effect on the contractility of the respiratory muscles.

Our results show that upper abdominal surgery decreases inspiratory and expiratory muscle strength and that aminophylline has a protective effect only on inspiratory muscle function. Although aminophylline showed no significant effect on lung volume indices, its effect on inspiratory muscle strength may be of clinical importance in its ability to reduce pulmonary complications after abdominal surgery. Aminophylline could have a specific application in patients with pulmonary disease undergoing upper abdominal surgery in whom the respiratory muscles are disadvantaged as a result of hyperinflation.

We wish to acknowledge Glaxo ABEE, Greece for supporting this research by a grant and Mrs $\mathbf{N}$ Bizaki for typing the manuscript. 
Preliminary results of this study have been presented at the SEPCR-SEP Joint Meeting in Paris, 1989, and published in abstract form in Bull Eur Physiopathol Respir 1989;22:161.

1 Wightman JAK. A prospective survey of the incidence of postoperative pulmonary complications. Br f Surg 1986; postopera

2 Laszlo G, Archer GG, Darrell JH, Dawson JM, Fletcher $\mathrm{CM}$. The diagnosis and prophylaxis of pulmonary complications of surgical operation. Br f Surg 1973; 602:129-34.

3 Rehder K, Sessler AV, Marsh HM. General anesthesia and the lung. Am Rev Respir Dis 1975;112:541-63.

4 Craig DB. Postoperative recovery of pulmonary function. Anesth Analg 1981;60:46-52.

5 Latimer RG, Dickman M, Day WC, Gunn ML, Schmidt DC. Ventilatory patterns and pulmonary complications after upper abdominal surgery determined by preoperative and postoperative computerized spirometry and tive and postoperative computerized spirome
blood gas analysis. $A m \mathcal{F}$ Surg 1971;122:622-32.

6 Ali J, Weisel RD, Layug AB, Kripke BJ, Hechtman HB. Consequences of postoperative alterations in respiratory mechanisms. Am $\mathcal{F}$ Surg 1974;128:376-82.

7 Westbrook PR, Stubbs SE, Sessler AD, Rehder F, Hyatt RE. Effects of anesthesia and muscle paralysis on respiratory mechanisms in normal man. $f$ Appl Physiol 1973;34:81-6.

8 Ford GT, Whitelaw WA, Rosinal WT, Gruse PJ, Guentir CA. Diaphragm function after abdominal surgery in humans. Am Rev Respir Dis 1983;127:431-6.

9 Simonneau G, Vivien V, Sartene R, Kunstlinger F, Samil $\mathrm{K}$, Noviant $\mathrm{Y}$, et al. Diaphragmatic dysfunction induced by upper abdominal surgery: role of postoperative pain. Am Rev Respir Dis 1983;128:899-903.

10 Dureuil B, Vires N, Cantineau JP, Marty C, Aubier M, Desmonts JM. Diaphragmatic contractility after upper abdominal surgery. F Appl Physiol 1986;61:1775-80.

11 Froese AB, Bryan AC. Effects of anesthesia and paralysis on diaphragmatic mechanisms in man. Anesthesiology 1974;41:242-54.

12 Tahir AA, George RB, Weill $\mathrm{H}$, Adriani J. Effects of abdominal surgery upon diaphragm function and regional ventilation. Int Surg 1973;58:337-40.

13 Dureuil B, Desmonts JM, Mankikian B, Prokocimar P. Effects of aminophylline on diaphragmatic dysfunction after upper abdominal surgery. Anesthesiology after upper

14 Black LF, Hyatt RE. Maximal respiratory pressures: normal values and relationship to age and sex. Am Rev Respir Dis 1969;99:696-702.

15 Siafakas NM, Salesiotou V, Filaditaki V, Tzanakis N, Thalassinos N, Bouros D. Respiratory muscle strength in hypothyroidism. Chest 1992;102:189-94.

16 Cotes JE. Lung function. 4th edn. Oxford: Blackwell, 1979:365-87.

17 Parbrook GD, Dalrymple DG, Steel DF. Personality assessment and postoperative pain and complications. $\mathcal{f}$ Psychosom Res 1973;17:277-80.

18 Aubier M, De Troyer WA, Sampson M, Macklem PT, Roussos C. Aminophylline improves diaphragmatic contractility. N Engl $\mathfrak{f}$ Med 1981;305:249-52.

19 Aubier M. Pharmacotherapy of respiratory muscles. Clin Chest Med 1988;9:311-24.

20 Moxham J. Aminophylline and respiratory muscles: an alternative view. Clin Chest Med 1988;9:325-36. 